\title{
O LUGAR DO LIVRO E DA LEITURA NO MARANHÃO OITOCENTISTA: O GABINETE PORTUGUÊS DE LEITURA
}

\author{
THE PLACE OF THE BOOK AND OF THE READING IN MARANHÃO STATE \\ IN THE 19TH CENTURY: THE PORTUGUESE OFFICE OF READING
}

\author{
César Augusto Castro ${ }^{1}$ \\ Samuel Luis Velázquez Castellanos ${ }^{2}$
}

\begin{abstract}
RESUMO
Os catálogos de biblioteca têm se constituído como importante recurso para o resgate da história do livro e dos processos de produção, circulação e das práticas leitoras em diferentes lugares e por públicos distintos. Apresenta-se o catálogo da biblioteca do Gabinete Português de Leitura do Maranhão, destacando a trajetória do livro no Maranhão no período oitocentista, como forma de compreender o processo de circulação e finalidades desse bem cultural; a história do Gabinete Português de Leitura, pontuando suas normas, finalidades e critérios normativos para os associados; e a análise do catálogo da Biblioteca desse instituto, destacando a classificação e ordenação dos livros, bem como as principais classes consultadas. Constata-se que este catálogo foi elaborado como forma de desenvolver estratégias de controle e consulta ao acervo, além de verificar a natureza das obras e indicar as leituras permissivas na biblioteca.
\end{abstract}

PALAVRAS-CHAVE: Gabinete Português de Leitura. Biblioteca. Catálogo.

\begin{abstract}
The library catalogs have been established as an important resource for the rescue of book history and the processes of production, circulation and reading practices in different places and for different audiences. We present a catalog of the library of Portuguese Reading Cabinet in Maranhão, highlighting the history of the book in Maranhão in nineteenth-century period, as a way to understand the process and purpose of this cultural movement as well; the history of Portuguese Reading Cabinet, punctuating his standards, objectives and regulatory criteria for members; and the analysis of the catalog of the library of this institute, highlighting the classification and ordering of books, and the main classes consulted. It appears that this catalog has been prepared in order to develop strategies to control and consult the collection and to verify the nature of the works and indicate the permissive readings in the library.
\end{abstract}

KEYWORDS: Portuguese Reading Cabinet. Library. Catalog.

\section{INTRODUÇÃO}

Neste texto trataremos do catálogo de biblioteca do Gabinete Português de Leitura no Maranhão. Essa fonte possibilita ao investigador, dependendo do seu interesse, inúmeras possibilidades interpretativas, tais como: a produção, a circulação e o consumo do livro em um dado lugar, em períodos determinados ou por diversificada parcela de leitores; a análise por temáticas distintas, por autores vários, pela tipologia das edições; e a compreensão pelos

\footnotetext{
${ }^{1}$ Professor associado III da Universidade Federal do Maranhão, atuando no Programa de pós-graduação em educação e história e no Departamento de Biblioteconomia. E-mail: ccampin@terra.com.br

${ }^{2}$ Doutor em Educação. Professor Adjunto II/UFMA. São Luis, Maranhão, Brasil. E-mail: samuel@ufma.br

Recebido em: 25/02/2015 - Aceito em: 29/04/2015
} 
processos de liberdade ou de censura às formas de expressão e de pensamento, contidos nesses suportes culturais, assim como o seu uso como material escolar.

Sobre esse tipo de fonte, não localizamos trabalhos que a abordem enquanto instrumento de investigação, para que se possa compreender a produção e a circularidade do livro no âmbito das instituições escolares. Algumas apreensões sobre a importância dos catálogos foram feitas a partir de Grafton (2006) e Ong (2005), mas é o estudo desenvolvido por Vidal (1995), O exercício disciplinado do olhar - livros, leituras e práticas de formação discente no Instituto de Educação do Distrito Federal (1932-1937), que se constitui como referencial importante para entendermos o acervo de bibliotecas como meio de formação das práticas leitoras.

Exposto isso, inferimos que há uma lacuna tanto no campo da história da educação, como também na história do livro, ao referirmos à análise do catálogo como estratégia metodológica para entendermos, no tempo, o lugar do livro no interior (ou não) das instituições escolares, e como importante recurso recreativo para públicos distintos. Para Buonocore (1976), o objetivo de um catálogo é identificar os itens descritivos capazes de identificar os livros pelos seus dados (autor, título e assunto, por exemplo) e pela sua localização no espaço da biblioteca. Essa forma clássica utilizada pelos catalogadores para distribuir e identificar o acervo tem sido uma prática usual desde as origens das bibliotecas, na tentativa de "conciliar a arrumação material das obras com a divisão dos saberes, ou até mesmo pelo sonho de contiguidades significantes em que a proximidade física dos livros nas prateleiras traçaria itinerários intelectuais e heurísticos" (JACOB, 2000, p. 13).

Sendo assim, este ensaio tem a finalidade de examinar o catálogo da Biblioteca do Gabinete Português de Leitura no Maranhão, publicado pela Tipografia de Frias, em São Luís, em 1867. Assim, dividimos este trabalho em duas partes: na primeira, mergulhamos na trajetória do livro no Maranhão nos Oitocentos, relacionando-o aos processos educacionais; e na segunda, debruçamo-nos sobre o Gabinete Português de Leitura e na análise do catálogo da sua biblioteca.

\section{A CIRCULAÇÃO DAS MATERIALIDADES CULTURAIS NO CENÁRIO MARANHENSE OITOCENTISTA}

Ao debatermos sobre a leitura, o livro e as práticas leitoras no Maranhão, temos que concordar com a visão de Andrade (1969, p. 65) quando afirma que "não existe ainda um estudo que se possa considerar completo e recomendável sobre a [sua] evolução". Se para Viveiros (1954), até a independência, o comércio do livro no Maranhão era praticamente nulo, para Castro (2005), o início do livro nas terras maranhenses começa com a presença dos franceses, em 1612. Essa datação é depreendida por meio de trechos da História da Missão dos Padres Capuchinhos na Ilha do Maranhão e terras circunvizinhas (ABBEVILLE, 1945), no qual descreve que cruzes, breviários e leituras bíblicas faziam parte das ações dos 
descobridores para que os nativos abraçassem o cristianismo da Igreja de Deus ${ }^{3}$. Se não foram eles a desenvolverem uma formação leitora, os jesuítas, ao fundarem, em 1622, o Colégio da Nossa Senhora da Luz, em São Luís, fazem como leitura obrigatória dos noviços as obras de Descartes, de Ovídio e de Cervantes. Essas práticas leitoras, segundo Meireles (1994, p. 52), foram exigidas em 1731, no "Colégio e Residência da Madre de Deus, [colégio jesuítico], onde era ensinado Teologia, Filosofia, Retórica e Primeiras Letras". Na visão de Leite, em História da Companhia de Jesus no Brasil, a biblioteca "estava muito bem instalada em sala especial onde cabiam 5000 volumes" (LEITE, 1938, p. 79). Por constituir o ensino, a presença do livro e da leitura maranhense não era prioridade dos inacianos, mas práticas regulares de tantas outras ordens religiosas: dos Carmelitas, dos Mercedários e dos Franciscanos (MORAES, 2006).

No século XIX, a partir da expansão da educação maranhense, notadamente a partir de 1838 com a criação do Liceu, e sem perder a referência a outras iniciativas educativas, particulares e públicas, como o Recolhimento de Nossa Senhora de Anunciação e Remédios, a Casa dos Educandos Artífices, a Escola Agrícola do Cutim e o Asilo de Santa Teresa, inaugurou-se a fase que denominamos de período de sistematização de um pensar e de um fazer pedagógico e, por conseguinte, de uma produção de livro e da leitura no Maranhão. Tal movimento educativo, a nosso entender, ocorreu por vários motivos, sendo o principal a ampliação das oportunidades de educação das primeiras letras em várias freguesias, termos e comarcas, inclusive nas escolas rurais, como verificamos no montante de documentos legislativos no período de 1835 a 1889 (CASTRO, 2009).

Em relação às bibliotecas no Maranhão, sabemos de poucos estudos, tais como os desenvolvidos por Moraes (1973) e Braga (2002). Mas, certamente, são os trabalhos de Pinheiro (2004) e Silva (2008) nos quais podemos encontrar, com maior consistência de dados, a trajetória da Biblioteca Pública no Oitocentos. Um documento revelador das bibliotecas e, também, dos livros e da leitura no Maranhão do século XIX, é o relatório de Gonçalves Dias, incumbido pelo Governo Imperial a inspecionar a situação dos livros e das bibliotecas conventuais no Norte do Brasil. Nele descreve que:

\begin{abstract}
é o convento de Santo Antonio o que mais avulta, contendo uma biblioteca de dois volumes; mas por negligência, acham-se muitos, quase todos, danificados a ponto de não poder servir. Estão arrumados em sete ou oito estantes sem ordem alguma e colocados em uma sala incômoda para estudo, por ser vivamente ferida pelo sol, sem uma mesa de estudo, sem uma cadeira [...]. Não havendo catálogos de biblioteca tive de percorrer os volumes um por um para que ao menos soubesse o que eles continham e na esperança de encontrar entre eles livros dos que faltam nas nossas bibliotecas ou algum manuscrito esquecido. Nada disso: são volumes de
\end{abstract}

\footnotetext{
${ }^{3}$ Sobre a presença francesa no Maranhão, destacamos o trabalho da Prof ${ }^{\mathrm{a}}$ Maria de Lourdes Lauande Lacroix, que discute o mito de fundação da cidade de São Luís, explicitando como no início do século XX as elites ludovicenses reinterpretaram a chegada da expedição de La Ravardière, em 1612. Ao publicar a obra $A$ Fundação Francesa de São Luís (2002), a pesquisadora causa, segundo Ribeiro (2006) e Sousa (2007), estilhaços na intelectualidade maranhense (jornalistas, acadêmicos e escritores) em manifestações escritas nos jornais locais. Maiores detalhes desse assunto podem ser obtidos na leitura do artigo de Jhonatahan Uelson Pereira Sousa, Os Estilhaços - debate intelectual sobre a fundação francesa de São Luís do Maranhão. Disponível em: <www.outros. tempos.uema.br >, v.4, p.111-134, 2007. Acesso em: 27 mar. 2010.
} 
teologia causística, de filosofia rançosa, que ao abrir-se pareciam estranhar e queixar-se da mão que os importunava no descanso morto em que jaziam. Para toda literatura, o teatro de Voltaire e Matastático e não sei de alguns volumes truncados das décadas de Barros. Por toda a ciência. Montesquieu, envergonhado de se achar entre uma álgebra escrita em latim [...]. Eis a livraria de Santo Antonio que é a melhor de todas as ordens religiosas do Maranhão. [...]. As Mercês tiveram em outro tempo uma grande e vasta livraria; lembram-se ainda algumas pessoas do tempo em que frequentando escolas lá iam com seus companheiros gazear na livraria do convento, e por brinquedo se atiravam com os livros uns aos outros, sem que alguém interviesse para lhes por cobro. Estragaram-se ou desapareceram; o que resta cabe em três pequenas prateleiras, arrumadas de topo, sem uma ordem mais que as teias de aranha que os ligam [...] a do Carmo carece de tudo, livros, estantes e local para eles [...] da livraria e arquivo dos jesuítas em 1831 não se acham senão mil volumes e esses completamente destruídos (DIAS, 1973, p. 8).

Segundo Viveiros (1954), a primeira casa de livros em São Luís foi a Repartição do Correio, no século XVIII, que, pela falta de leitores-compradores, fechou em 1802. Essa falta de leitores devia-se, sobretudo, ao índice representativo de analfabetos, inclusive entre a burguesia. Parece que nessa época o livro era objeto de "repugnância destes povos" (VIVEIROS, 1954, p. 340). Os poucos leitores privilegiavam os almanaques e as obras hagiográficas. Por sua vez, as poucas bibliotecas existentes se encontravam em estado precário, servindo mais como local de encontro dos jovens do que de leitura ou estudo, como referido por Gonçalves Dias.

A tipografia, introduzida somente em 1821, contribuiu para uma produção e circulação de textos de maneira mais ampla e consistente, especialmente a partir da publicação de jornais e folhetos. Para Marques (1970, p. 340), "em meados do século XIX, a produção de livros, como manifestação incidental da prosperidade maranhense, alcançara um alto padrão de excelência técnica e estética e volume suficiente para chamar a atenção para as edições provinciais". Somente com a expansão das casas tipográficas os livros passaram a ser editados na Província, destacando-se, entre elas, a de Frias e de Berlamino de Mattos, os maiores impressores do Maranhão no Oitocentos (HALLEWELL, 2005). Essas tipografias contribuíram para a circulação em jornais os anúncios de compra e venda de livros vindos de Portugal, da Inglaterra e, principalmente, da França, que tratavam de filosofia, direito, línguas, dentre outros assuntos, a exemplo deste anúncio que circulou no Jornal Publicador Maranhense, em 26 de novembro de 1834:

João Antonio da Costa Rodrigues, rua da estrela n. 38, tem para vender por preços cômodos as seguintes obras:

Dicionário da Literatura por Lahaupe - 14 volumes

Dicionário da Indústria -6 volumes

Dicionário de Artes e Ofícios - 3 volumes

Dicionário de Química - 3 volumes

Lições de Direito - 2 volumes

História do Filosofismo Inglês - 2 volumes

História Crítica da Filosofia - 3 volumes

Filosofia da Natureza - 10 volumes

Teatro de Corneille - 10 volumes

O Grande Dicionário Geográfico - 10 volumes (PUBLICADOR, 1834,p.3) 
Tal venda de livros, ao rivalizar com outros produtos distribuídos no comércio local (como materiais de escritório, calçados, bebidas e roupas), conjuntamente com o aparecimento de livrarias (como as de Frutuoso, a francesa-portuguesa, a de Magalhães e a Universal, considerada esta última a mais completa pela diversidade de assuntos e autores) constituiu evidências da "rapidez com que os maranhenses se afeiçoaram ao convívio dos bons livros" (VIVEIROS, 1954, p. 343). Esse promissor mercado de livros contribuiu para que tipografias, anteriormente dedicadas à publicação de jornais e pequenas obras, se tornassem "editoras" e publicassem obras com tiragens grandiosas para a época, como o Livro do Povo (10.000 exemplares) e o Livro dos Meninos (6.000), distribuídos nas escolas da capital e nas cidades do interior da Província.

A Livraria Universal, localizada na Praça João Lisboa e fundada em 13 de junho de 1846, se insere no debate de Otto Sheneider em artigo publicado na "Revista do Livro", em 1957, sobre o título A mais antiga livraria brasileira. Neste texto, o autor discute a polêmica entre estudiosos brasileiros que "buscavam saber com exatidão qual [era] a mais antiga livraria brasileira, isto é, a livraria fundada há mais tempo e que não [tivesse] interrompido suas atividades até hoje" (SHENEIDER, 1957, p. 23). Para este autor, a mais antiga livraria do Brasil tinha sido criada por Carlos Poggetti, em Salvador, em 1835, passando a denominar-se Livraria Catilina quando Xavier Catilina assumiu a sua direção. A segunda, Ao Livro Verde, tinha sido criada na Cidade de Campos, Estado do Rio de Janeiro, em 1844, constituindo-se a Universal, a terceira livraria em funcionamento. Mas entre todas as livrarias criadas no Brasil, a Francisco Alves, foi a que ganhou maior notoriedade, já que, além da venda de livros, se dedicava também à edição de "livros de ensino, com objetivo de libertar o Brasil da tutela dos livros estrangeiros" (SHENEIDER, 1957, p. 24), distinguindo-se essa livraria-editora por instituir entre nós o pagamento do direito autoral.

Se por um lado o crescimento das publicações e a circulação de livros contribuíram com a ampliação das oportunidades de ensino - do primário a partir de 1827, quando o governo central autorizou a criação de escolas de primeiras letras em todas as cidades, vilas e lugarejos mais populosos (período em que o Maranhão aumentara de 14 para 24 escolas, representando um passo na difusão da educação, do livro e da leitura), e do ensino secundário, por meio do Liceu Maranhense, criado em 1838, objetivando formar pretendentes ao ensino superior (CASTELLANOS, 2007) -, por outro, esse movimento em torno do livro e da leitura culminou com a criação de vários espaços destinados às práticas leitoras: a Biblioteca Pública, o Gabinete Português de Leitura, os grêmios literários e o crescimento quantitativo de jornais, inclusive aqueles que se destinavam a discutir a instrução na Província ${ }^{4}$. Portanto, podemos afirmar, com base na documentação até então pesquisada, que o livro (no sentido geral e, principalmente, os livros escolares) integrou o conjunto de elementos que formavam parte das salas de aulas - nas residências e nas escolas - na sociedade maranhense, inclusive nas instituições destinadas à educação de crianças (meninos e meninas) pobres e desvalidas.

\footnotetext{
${ }^{4}$ Por exemplo, o Jornal de Instrução e Recreio (1845) e o jornal A Escola (1878).
} 


\section{OS LIVROS E O GABINETE PORTUGUÊS DE LEITURA}

O Gabinete Português de Leitura foi fundado em 9 outubro de 1853, embora existam poucas informações disponíveis no Arquivo Público do Estado (o seu estatuto e o regulamento) e na Biblioteca Pública Benedito Leite, apesar de sabermos que esta tinha como fim disseminar o gosto pela leitura, propiciando ao público bons livros de seu vasto acervo, além de patrióticas sessões cívicas e conferências ilustrativas. Nos Estatutos Provisórios desta sociedade (no Art. II, do Título I) ficam explícitos os fins propostos para fomentar a instrução e os meios a serem utilizados neste espaço de sociabilidade, fazendo-se necessário para objetivar seu funcionamento e concretizar seus desígnios a compra de livros escolhidos que tratassem sobre a ciência, a literatura e as artes, subscrever os mais creditados periódicos nacionais e estrangeiros, concernentes a estas áreas do saber, assim como instruir pelos meios possíveis, e compatíveis, aqueles acionistas que o desejassem (ESTATUTOS..., 1853).
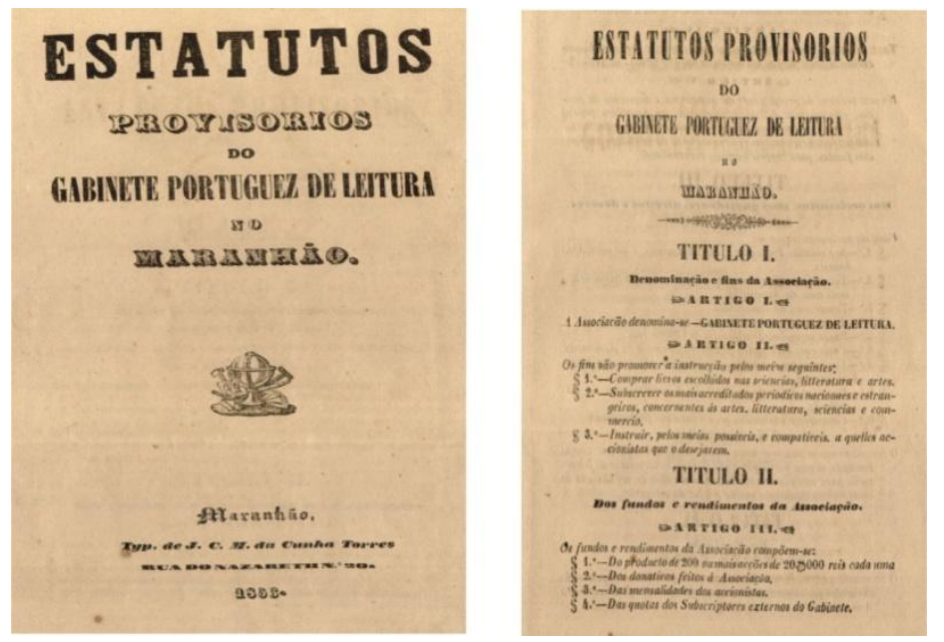

FIGURA 1: Estatutos provisórios do Gabinete Português de Leitura.

Fonte: Arquivo Público do Estado do Maranhão.

Segundo Art. 8. ${ }^{\circ}$ do Regulamento, "os sócios e subscriptores [poderiam] levar para ler em suas casas um volume por cada vez, [não podendo] exigir outro antes de restituir o que tiverem cedido" (ALMANAK..., 1866, p.98), pelo período de quatro a oito dias e penalizando o leitor com multa de $2 \$ 000$ rs. Pela perda ou destruição era cobrada a parte do valor das subscrições feitas por trimestres. Por outro lado, no Art. $5^{\circ}{ }^{\circ}$, era explicitamente proibido mexer nas estantes, “[...] devendo os livros ser pedidos ao Guarda, e a elle restituídos para os collocar na ordem estabelecida [...], devendo todos estar em necessário silêncio, a fim de não [perturbarem] os leitores" (ALMANAK..., 1866, p.99 ). Outra especificidade dessa biblioteca consistia na proibição de qualquer leitura no estabelecimento que não fossem as obras permitidas.

No Art. 9. ficou estabelecido que "só [podiam] ser lidos no Gabinete os dicionários, atlas, livros de consulta, assim como os que no catálogo tiverem a nota (N. S.) ${ }^{5}$, e os

\footnotetext{
${ }^{5}$ Apesar de várias tentativas não identificamos o significado de (N. S.).
} 
periódicos e folhas avulsas [...] conservados sobre as mezas à disposição dos leitores por espaços de 15 dias, sendo depois emmassados" (CATÁLOGO, 1967, p. 2). A medida foi adotada, talvez, para regular a entrada de público vinculado ou não à instituição, pelo espaço limitado da biblioteca, pelo simples controle da leitura das obras, ou mesmo como estratégia para manter a dinâmica de empréstimo/devolução, visando a circularidade dos livros, a captação de novos leitores e, portanto, a entrada de novos subscritores; ainda que Marques (1970) já nos tenha informado em seu relatório que esse lugar de leitura fosse “[...] frequentado regularmente por 5 ou 6 pessoas por noite" (MARQUES, 1876, p. 48).

A partir do regulamento e dos estatutos, pode-se apreciar as estratégias de imposição dos livros e das leituras, como também as normas de comportamento que deviam seguir os leitores e o público específico com o qual interagia. Entre avisos e anúncios de naturezas várias, e na disputa de espaços por divulgação entre os diversos jornais, eram noticiadas as tentativas de reorganização e operosidade dessa instituição, promovidas por alguns associados para garantir sua existência (depois de funcionar 18 anos de forma ininterrupta). $\mathrm{O}$ agenciamento de conferências e a promoção de "[...] cursos para a instrução de sócios e outras pessoas que [quisessem] aproveitar essa oportunidade, [não sendo difícil] para aqueles quem tem fortuna [...] ajudar a instituição digna de proteção pública"( PUBLICADOR..., 1871, n.57, p.2), constituíam estratégias que garantiam a manutenção e funcionalidade deste espaço de livros, leituras e leitores.

$\mathrm{Na}$ aquisição de livros pelo Gabinete Português de Leitura e anunciados n'O Publicador Maranhense (1871), podemos citar: O Descobrimento da América, por Campe (2 vols); O Descobrimento de Portugal, por Damião Antonio de Lemos (20 vols); História da Revolução Francesa, por Desodoards; História Natural, de Plínio (vertida do latim, 2 vols); História da Independência de América, por C. Botta; a História de S. Francisco Xavier, por Lucena (4 vols); e De frei Bartholomeu dos martyres, escrita por frei Luiz de Souza (2 vols). Por outro lado, e em outras áreas do conhecimento, aponto para o Compêndio de Geografia, por Geraldes (1 vol), e a Geografia (em latim e grego), de Strabão (1 vol); o Dicionário de Botânica, por Benevides (1 vol) e a Methamorphoses de Ovídio, por Castilho (1 vol); as Obras Completas, de Montesquieu (9 vols) e as de Flechier (bispo de Nymes em 10 vols); assim como a Biblioteca Universal e a Gramática Espanhola, entre outras produções de diferentes gêneros.

Seu acervo, em 1866, era formado por 4000 volumes (ALMANAK..., 1866), mas durante doze anos seu estoque foi incrementado, ampliando o quantitativo de títulos para 4367, distribuídos em 8000 volumes, isto é, o gabinete achava-se "[...] muito augmentado e consideravelmente melhorado" na opinião de José Rodrigues de Araujo, o guarda-livros desta biblioteca(MARQUES, 1876). Esses dados ao serem comparados, com os relatórios expostos por Rego (1875) e por Marques (1876) que apresentam discrepâncias no que se refere ao inventário de obras. As notificações entre estes autores diferem, destoando também com as informações registradas pelo guarda-livros desta associação. Se para Rego (1875) o Gabinete Português de Leitura continha 5479 volumes, em 1876, para Marques, no ano posterior, este espaço de leitura continha 4000 obras referentes a onze mil volumes. 
Apesar do desencontro das informações contidas no inventário e nos relatórios apresentados às exposições citadas, no que se refere ao cômputo de títulos e volumes desse espaço cultural, seja pela compra e doações de novas obras, seja pelos extravios ou deteriorações, o importante é entender que este lugar de livros, de leitura e de leitores só podia ter como sócios os "súbditos portugueses", de acordo com o Regulamento e os estatutos. Entretanto, qualquer pessoa que tivesse bom comportamento e boa aparência poderia se subscrever e usufruir da instituição, independente do sexo e da nacionalidade, como determinava o título XVIII, do artigo XXI dos seus estatutos:

\$1 Que sejam pessoas bem morigeradas e de occupação honesta.

\$2 Que tenhão meios sufficientes para responder por qualquer extravio que dêem aos livros, ou objectos que levarem do Gabinete.

\$ 3 Que paguem adiantado o importe da subscripção que será - por mez $1 \$ 300$ reis, por 6 meses $6 \$ 000$ reis, e por um anno $12 \$ 000$ reis (ESTATUTOS.., 1853, p.7).

Ao identificar nos títulos divulgados que as temáticas expostas correspondiam às diversas esferas do saber e a campos disciplinares específicos (história, gramática, geografia, botânica, filosofia e religião), o Gabinete Português de Leitura, a partir de seu acervo, não só poderia ser considerado como um ambiente de formação do leitor, mas um lugar de consulta e auxílio na instrução e na educação maranhense, por fazerem parte de seu estoque os livros escolares ou obras utilizadas no ensino. Por outro lado, a presença de diferentes gêneros de escrita e temáticas de entretenimento faziam parte de sua aquisição, "[...] com o fim de offerecer aos seus associados e subcriptores leitura amena e agradável, havendo muito cuidado no escolher das obras"(ALMANAK... 1878, p.115).

Os livros como o Último rei dos franceses, por Alexandre Dumas (4 vols); as Poesias, de Faustino X de Novaes (1 vol) e de Antonio da Cruz e Silva (6 vols); e a Revista Popular, de I. M. Campello (1 vol) ( PUBLICADOR..., 1857, p.3), embora pertencessem ao grupo de leituras não permitidas para serem lidas na instituição, de acordo com o Art. $7^{\circ 6}$., ainda assim foram divulgadas, postas em circulação e consumidas por mediação dos empréstimos.

Mesmo que as leituras de obras dessa natureza não fossem autorizadas no local, estas regras foram se constituindo em estratégias de autofinanciamento, adotadas pelo Gabinete Português de Leitura, uma vez que com a circulação dos livros, através do sistema de empréstimo e devolução, promoviam o interesse por novas obras, a captação de outros leitores e, por suposto, a integração de novos subscritores em defesa da estabilidade da instituição. Essas regras internas, ao mesmo tempo em que garantiam a sobrevivência e o funcionamento do estabelecimento, também denunciavam a dependência da manutenção do local pelas doações de particulares e pelas mensalidades dos contribuintes.

Os fundos e os rendimentos da associação provinham "do producto de 200 ou mais acções de $20 \$ 000$ reis cada uma, dos donativos feitos á Associação, das mensalidades dos

${ }^{6}$ É expressamente prohibido mexer nas estantes, para que não seja transformada a ordem de collocação dos livros. 
accionistas e das quotas dos Subscriptores externos do Gabinete" (ESTATUTOS..., 1853, p.1). Desta forma, fica evidente por meio da análise e da compreensão do Regulamento e dos estatutos, a total responsabilidade dos associados portugueses pela sustentação dessa biblioteca, as proibições inerentes à leitura de textos não indicados como estratégia de circulação, divulgação e consumo dos livros, visando à captação de novos leitores e subscritores, às exigências e regras impostas a um público específico e restrito, e ao evidente desinteresse e à não obrigação do governo com o zelo da dita instituição.

Portanto, esta biblioteca, apesar de ter sido considerada, segundo os jornais, um espaço do cultivo às letras que promovia o convívio com os livros, e um lugar que propagava a instrução, estimulando o cultivo à leitura - por políticas pontuais no período em estudo, por representações sociais culturalmente enraizadas e pela defesa de interesses partidários em detrimento do bem comum -, traz as marcas de um predomínio elitista, as mazelas de uma cultura excludente e a concepção estreita de um espaço de sociabilidade para um público determinado (com boas maneiras e com emprego garantido). Sendo assim, partindo dos dispositivos mobilizados no seu Regulamento interno e as regras estabelecidas nos estatutos, foi negada a esta instituição, no transcurso de sua existência, ser concebida e aceita como um lugar de encontro entre sujeitos leitores de diferentes clivagens sociais, e um espaço de leitura com diferentes perfis de leitores.

As estratégias adotadas para sua subsistência, manutenção, organização e funcionamento, como também para a sua operacionalização por sujeitos defensores da cultura, das letras e da instrução (ainda que num circuito de sociabilidade restrito e estreito), não impediram que esta biblioteca perdesse força como espaço institucional no decorrer do Império, não evitou que se fosse descaracterizando como local de guarda da cultura escrita e não inibiu o seu desaparecimento gradual, acompanhado dos senões do próprio regime em vias de mudanças e extinção; embora sua memória tenha ficado no imaginário societal maranhense como um lugar que estimulou a leitura, que garantiu o vínculo estreito com os livros, e que se destacou pela proliferação de novos leitores no Maranhão imperial. Para Antonio Pedro Salgado, na sua crônica da Revista Elegante, em 1896, era "[...] triste ver leitores e leitoras, o abandono das lettras e das bellas artes entre nós [podendo] dizer que a Athenas se converteu em Boemia, [tendo] desaparecido por falta de leitores, a única biblioteca que [possuíamos]: o Gabinete Português" (REVISTA..., 1896, p. 3).

O catálogo ${ }^{7}$ desta instituição foi publicado em São Luís do Maranhão, em 1867, pela Tipografia de Frias. Esta tipografia com a de Belarmino de Matos eram as casas impressoras mais importantes da província nos Oitocentos (HALLEWEEL, 2005).

\footnotetext{
${ }^{7}$ Catálogo de Biblioteca é entendido neste trabalho como "conjunto das notícias bibliográficas dos documentos e livros de uma biblioteca, acompanhada da sua colocação na estante e elaborada de acordo com regras específicas. Catálogo bibliográfico. Catálogo de identidade” (FARIA; PERDIGÃO, 2008, p. 228).
} 


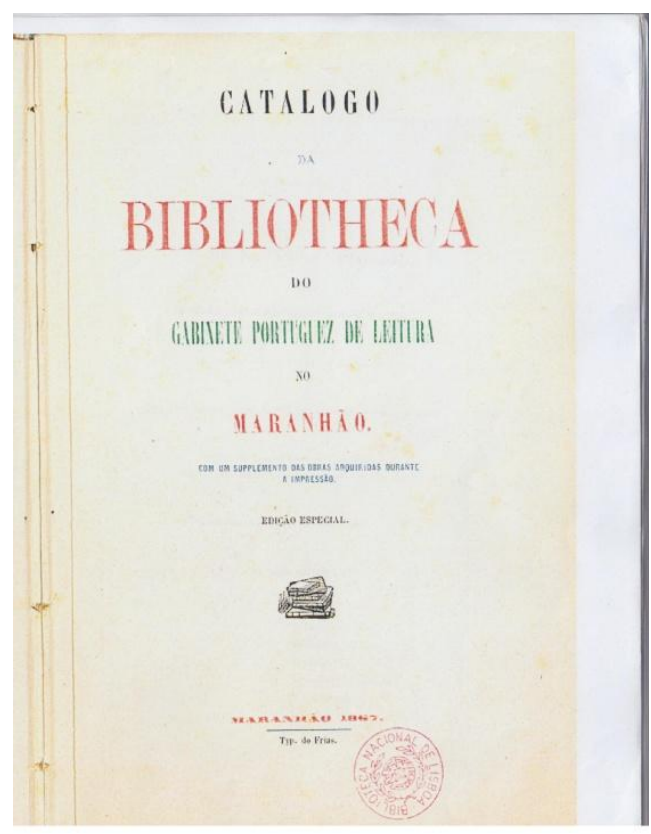

FIGURA 2 - Capa do Catálogo da Biblioteca do Gabinete.

Fonte: Catálogo, 1867.

Provavelmente, este catálogo tenha sido inspirado no Manual du Librarie et d'Amateur, publicado em Paris, em 1810, e adotava o sistema de Brunet, que apresentava uma notação mista e complexa que combinava algarismos arábicos e romanos, letras maiúsculas e minúsculas. Esse sistema influenciou a organização do catálogo da Biblioteca Nacional de Paris, da Biblioteca de Sainte Geneviéve e do British Museum, de Londres.

Sendo assim, este catálogo arrolava o conjunto de livros que compunham o acervo da biblioteca e estava dividido em duas partes. A primeira, em 162 páginas, tratava dos aspectos introdutórios, a divisão dos livros por área e o rol dos mesmos. Os livros eram organizados por assuntos e em ordem alfabética, com indicativo da $1^{\circ}$ letra inicial e final no início da página. A $1^{\mathrm{o}}$ classe (Romance, Novela e Conto) estava distribuída em 60 páginas, sendo que somente algumas das descrições apresentavam a sinalização do gênero literário. As entradas, em sua maioria, identificavam o nome do autor, título, local, casa publicadora e data da publicação. A segunda parte trazia um "suplemento ao catálogo", com apenas quatro páginas. Esta publicação foi dedicada ao

Ilmo Sr. Delfim da Silva Guimarães, presidente da Associação do Gabinete Portuguez de Leitura, que lhe tem prestado valiosíssimos serviços que lhe consagra todos os seus momentos de repouso: Àquelle que - sem ser ainda sócio benemérito - é, todavia, o mais benemérito de todos os sócios do Gabinete. (CATÁLOGO, 1867, p.1).

Esta dedicatória foi assinada pelos membros da época do Gabinete, portugueses com expressiva importância no comércio, na indústria e nas artes maranhenses: J. Marques da Silva, Marianno M. da Matta, M. Correa Lima, Germano M. d’Assumpção, A. J. d'Azevedo, J. M. C. de Frias. Após esta página, A. J. de Azevedo publicou uma poesia em que destacou o 
papel e a relevância do estabelecimento para a promoção da leitura e dos livros, e o sentido de ser português.

Raquítico arbusto plantado em terra inculta,

Eis-te hoje convertido em arvore viçosa!

Cercaram- te desvelos; o tempo fez-te adulta

Medraste. Floreceste, tornaste-te frondosa

E tronco majestoso que a copa se sustenta

O nome PORTUGUÊS; escudo, as nossas almas; (grifo do autor)

Amor da pátria, a seiva, o sol que te aviventa;

E frutos são os livros; e folhas, verdes palmas

\section{SALVE! SALVE! DE LEITURA}

GABINETE PORTUGUÊS (grifo do autor)

Lindo prado de verdura

Destes campos na aridez!

Jardim de Plantas mimosas

Onde os jasmins e as rosas

Vem os romeiros colher!

Fonte! Onde o peregrino

Para amenizar o destino

Vem doce néctar bebe! (CATÁLOGO, 1867, p.1).

Em seguida, constava uma parte do Regulamento Interno do Gabinete com recomendações para os subscritores ou assinantes (Art. $1^{\circ}, 2^{\circ}$ e $3^{\circ}$ ); disposições comuns aos sócios e subscritores, como, por exemplo, os dias e os horários de funcionamento da biblioteca (Art. $4^{\circ}$ ao $15^{\circ}$ ), e o índice do catálogo. Este índice apresentava os livros divididos em vinte e uma classes bibliográficas, onde se destacava o assunto remetendo para a correspondente paginação; o número de títulos existentes e o total de exemplares que, na época da sua publicação, totalizavam 2802 obras e 4892 exemplares, incluindo as obras descritas no suplemento (CATÁLOGO, 1867, p. 1).

Ressaltamos que no catálogo não constava o rol de periódicos (jornais e revistas) que compunham o acervo da biblioteca, apesar desses itens constarem como obras existentes ${ }^{8}$. As obras gerais, como as gramáticas, dicionários, atlas e demais livros de consultas, eram franqueados aos leitores apenas para consulta interna. Com relação aos jornais, estes deveriam ficar expostos para os leitores durante 15 dias, sendo em seguida encaminhados para encadernação e armazenamento em armários destinados para este fim.

Desse total de obras existentes no acervo, predominavam: romance, história, poesia, filosofia e obras religiosas, com menor incidência para física e química, arquitetura, belas artes, bibliografia, conforme demonstrado no quadro abaixo.

\footnotetext{
${ }^{8}$ Art. $9^{\circ}$ : Os atlas, diccionarios e mais livros de consulta, e os que no Catalogo tiverem a nota (N. S.) só poderão ser lidos no Gabinete; bem assim, os periódicos e folhas avulsas, os quaes se conservarão sobre as mezas por espaço de 15 dias, sendo depois emmassados (CATÁLOGO, 1867, p. 2).
} 
QUADRO 1 - Índice do Catálogo.

\begin{tabular}{|l|l|l|l|}
\hline Classes & \multicolumn{1}{|c|}{ Assuntos } & Títulos & Volumes \\
\hline I & Romances, Novelas, Contos, etc. & 1209 & 2177 \\
\hline II & Crítica e Literatura & 189 & 472 \\
\hline III & Tragédias, Dramas, Comédias, etc. & 100 & 121 \\
\hline IV & Poesias & 265 & 361 \\
\hline V & $\begin{array}{l}\text { Gramáticas, Dicionários, } \\
\text { Educação Moral, etc. }\end{array}$ & 87 & 108 \\
\hline VI & História & 208 & 499 \\
\hline VII & Antiguidades e Nobiliária & 10 & 14 \\
\hline VIII & Bibliografia & 14 & 28 \\
\hline IX & Biografia e Necrologia & 53 & 162 \\
\hline X & Geografia, Viagens, etc. & 99 & 134 \\
\hline XI & História Natural & 35 & 52 \\
\hline XII & Física e Química & 24 & 37 \\
\hline XIII & Matemáticas & 38 & 40 \\
\hline XIV & $\begin{array}{l}\text { Filosofia, Cultos e Materiais } \\
\text { Eclesiásticos }\end{array}$ & 135 & 229 \\
\hline XV & Medicina, Cirurgia, etc. & 33 & 41 \\
\hline XVI & Jurisprudência e Legislação & 58 & 92 \\
\hline XVII & Política e Administração & 83 & 105 \\
\hline XVIII & $\begin{array}{l}\text { Economia Política, Estatística, } \\
\text { Comércio, etc. }\end{array}$ & 74 & 104 \\
\hline XIX & $\begin{array}{l}\text { Agricultura, Economia Rural e } \\
\text { Doméstica, Higiene, etc. }\end{array}$ & 44 & 53 \\
\hline XX & $\begin{array}{l}\text { Arquitetura, Belas Artes, Indústria, } \\
\text { Ofícios }\end{array}$ & 34 & 46 \\
\hline XXI & Maçonaria, Jogos, Fisionomia & 10 & 17 \\
\hline & TOTAL & 2802 & 4892 \\
\hline
\end{tabular}

Fonte: Catálogo, 1867.

Essa sistemática correspondia à forma de organização do acervo nas estantes e espaços físicos da biblioteca, isto é, em cada classe era inserido os assuntos relacionados: contos (classe I), crítica (classe II), drama (classe III), até zoologia (classe XI). Cada livro recebia uma identificação numérica na lombada que correspondia a sua posição na estante, por exemplo, a obra As amazonas, de D. Pedro Matta, estava na classe I, identificação 2420, maneira pela qual os leitores do Gabinete localizavam no catálogo a obra que gostariam de ler nas estantes. Como forma de manter essa ordem, era expressamente proibido aos consulentes "mexerem nas estantes, para que não seja transportada a ordem de colocação dos livros” (REGULAMENTO..., 1854. 7).

Os idiomas predominantes na biblioteca eram o português, seguido do francês, italiano e espanhol. No catálogo, todas as obras em língua estrangeira estavam com o título destacado, ou seja, "todas as obras impressas em língua estrangeira vão com o começo do título em itálico, afim de mais facilmente se distingui-los dos portugueses" (CATÁLOGO, 1867, p. 1).

Com relação à data de publicação dos livros, predominava as impressas no século XIX, posterior à década de 1840, o que demonstrava uma preocupação em manter o acervo 
atualizado. Em menor proporção, as impressas em datas posteriores estavam os romances, as obras de direito e medicina. Por sua vez, as obras escritas ou traduzidas para o português traziam o selo das principais casas impressas de Lisboa e do Porto, sendo que desta cidade predominava os livros escolares, que ao entrarem na biblioteca ocupavam um espaço separado dos demais, classificados na classe V, Educação.

Na última parte do catálogo, o suplemento, todas as obras incorporadas no acervo pertenciam à classe I, Romances, Novelas e Romances, e obras publicadas no Maranhão como a "Província" de Cesar Augusto Marques.

A partir da análise do catálogo é possível verificar a natureza dos suportes permitidos neste ambiente e identificar os títulos autorizados para o leitor, na tentativa de estabelecer relações entre as leituras permissivas nesta biblioteca particular e os livros indicados, aprovados, adotados e distribuídos na instrução pública.

\section{CONCLUSÃO}

A história do livro, da leitura e das bibliotecas no Brasil tem se mostrado um campo fértil de investigação pela possibilidade de compreendermos as formas de apropriação e a representação das diferentes modalidades do lido e do escrito, em tempo e espaços diversos. No Maranhão, "essas histórias" precisam ser melhor estudadas e pesquisadas pela posição política, econômica e social da Província/Estado, o que levou São Luís a ser cognominada de Atenas Brasileira.

No século XIX, período em que este texto se centra, não foram poucos os investimentos dos intelectuais para criarem espaços de sociabilidade, como bibliotecas, escolas, teatros e museus, de modo a contribuírem para formar uma sociedade letrada e instruída.

Insere-se nesse movimento a criação do Gabinete do Português de Leitura, criado em 1853 com a finalidade de propiciar ao público bons livros de sua variada biblioteca, formada por um acervo de obras portuguesas, brasileiras, francesas e de outras nacionalidades que faziam com que os maranhenses pudessem se inserir nos debates científicos e literários em voga nas nações mais desenvolvidas da Europa e dos Estados Unidos.

Uma das formas de conhecermos as diversas possibilidades de acesso ao conhecimento e à leitura é analisarmos catálogos de bibliotecas, de livrarias e das exposições científicas e literárias. Neste ensaio, tomamos como objeto de análise o catálogo do Gabinete Português de Leitura, publicado em 1867, pela Tipografia de Frias, na Cidade de São Luís, que nos possibilita compreendermos os diversos assuntos dos livros e a sistemática de organização do acervo da biblioteca dessa instituição, a qual, nos Oitocentos, era um espaço em que os letrados maranhenses recorriam para obterem materiais de leitura e estudo, além de trocarem ideias, debaterem política e traçarem os destinos da ilha de São Luís e da Província do Maranhão. 


\section{REFERÊNCIAS}

ABBEVILLE, Claude d. Historia da Missão dos Padres Capuchinos na ilha do Maranhão e terras circunvizinhas (1614). 2. ed. São Paulo: Livraria Martins, 1945.

ALMANAK administrativo, mercantil e industrial. São Luís: Tipografia do Publicador, 1866.

ALMANAK administrativo, mercantil e industrial. São Luís: Tipografia do Publicador, 1878 .

ANDRADE, Olympio de Souza. O livro brasileiro - progressos e problemas numa visão de conjunto. Revista do livro, v.12, n. 37, p. 11-53, abr.- jun, 1969.

BRAGA, Maria de Fátima Almeida. Práticas informacionais e sociedade da informação na Biblioteca Pública Benedito Leite. 2002. 176 f. Dissertação (Mestrado em Psicologia Social) - Universidade do Estado do Rio de Janeiro, 2002.

BUONOCORE, Domingo. Diccionario de Bibliotecologia. Buenos Aires Marymar, 1976.

CASTELLANOS, Samuel Luis Velásquez. Memória de leitura de professores e professoras maranhenses no século XX: estudo das primeiras décadas. 2007. $210 \mathrm{f}$. Dissertação (Mestrado em Educação) - Universidade Federal do Maranhão, 2007.

CASTRO, Cesar Augusto. Leis e regulamentos da Instrução Pública do Maranhão Império (1835-1889). São Luis: EDUFMA, 2009.

CASTRO, Cesar Augusto. Produção e circulação do livro e da leitura no Brasil: dos jesuítas (1550) aos militares (1970). Enc. BIBLI: Rev. Eletrônica de Bibl. Ci. Inform., Florianópolis, n. 20 , p. $93-103,2^{\circ}$ semestre de 2005.

CATÁLOGO da Biblioteca do Gabinete Portuguez de Leitura do Maranhão. Maranhão: Tipografia de Frias, em São Luis, 1867.

DIAS, Gonçalves. Relatório da Instrucção Pública. In: PRIMITIVO, Moacyr. Instrução Pública no Império. São Paulo: Martins Fontes, 1973, v. 2.

ESTATUTOS provisório do Gabinete Portuguez de Leitura do Maranhão. Maranhão: I. C. M. Cunha Torres, 1853.

FARIA, Maria Isabel ; PERICÃO, Maria da Graça. Dicionário do livro:

Da Escrita ao Livro Eletrônico. São Paulo: EDUSP, 2008. 
GRAFTON, Anthony. As origens trágicas da erudição: pequeno tratado sobre a nota de rodapé. Campinas: Papirus, 2006.

HALLEWELL, Laurence. O Livro no Brasil. São Paulo: EDUSP, 2005.

JACOB, Christian. Prefácio. In: Baratin, Marc JACOB, Christian. O poder das bibliotecas: a memória dos livros no Ocidente. Rio de Janeiro: Editora da UFRJ, 2000.

LIMA, Serafim. História da Companhia de Jesus no Brasil. Porto: Typografia do Porto, 1938.

MARQUES, César Augusto. Dicionário histórico - geográfico da província do Maranhão. 3. ed. [São Luis] : SUDENE, 1970

MARQUES, César Augusto. Breve noticia sobre a Província do Maranhão. São Luís: [s.n.] 1876.

MEIRELES, Mario. Dez estudos históricos. São Luís: ALUMAR, 1994.

MORAES, Jomar. Guia histórico da biblioteca pública Benedito Leite. São Luís: FUNC, 1973.

MORAES, Rubem Borba de. Livros e bibliotecas no Período Colonial. Brasília: Briquet de Lemos, 2006.

ONG, Walter. Oralidade e cultura escrita a tecnologização da palavra. Campinas: Papirus, 2005.

PINHEIRO, Ana Luiza Ferreira. Caminhos e descaminhos da Biblioteca pública da Província do Maranhão. 2004.87f. Monografia (Graduação em Biblioteconomia)Universidade Federal do Maranhão Luís, 2004.

PUBLICADOR MARANHENSE. São Luís: Tip. de I. J. Ferreira, 26 nov. 1834.

PUBLICADOR MARANHENSE. São Luis: Tip. de I. J. Ferreira, n. 53, 1857.

PUBLICADOR MARANHENSE. São Luís: Tip. de I. J. Ferreira, n. 57, 1871.

REGO, Fabio Hostillio de Moraes. Breve História sobre a Província do Maranhão. Rio de Janeiro: Tipografia da Reforma, 1875.

REGULAMENTO do Gabinete Português de Leitura. São Luis: I. C. M. Cunha Torres, 1854. 
REVISTA ELEGANTE, São Luís: Tip. de I. J. Ferreira, n. 2, 1896.

SHENEIDER, Otto. A mais antiga livraria do Brasil. Revista do Livro, v. 5, n.15, abr. jun, p. 23-27, 1957.

SILVA, Diana Rocha da. Recomeço de uma história: percurso histórico e a recriação da Biblioteca Publica na Primeira Republica. 2008. 102 f. Monografia (Graduação em Biblioteconomia)- Universidade Federal do Maranhão, 2008.

VIDAL, Diana Gonçalves. O exercício disciplinado do olhar livros, leituras e praticas de formação docente no Instituto de educação Federal (1932-1937). Tese (Doutorado em Educação) - Faculdade de educação da Universidade de São Paulo, 1995.

VIVEIROS, Jerônimo de. Historia do comércio do Maranhão (1612-1895). São Luís: Associação Comercial do Maranhão, 1954.

Como citar este documento:

CASTRO, César Augusto; VELÁZQUEZ CASTELLANOS, Samuel Luis. O lugar do livro e da leitura no Maranhão Oitocentista: o Gabinete Português de Leitura. Revista Digital de Biblioteconomia e Ciência da Informação, Campinas, SP, v. 13, n. 2, p. 243-258, maio/ago. 2015. ISSN 1678-765X. Disponível em: <http://periodicos.bc.unicamp.br/ojs/index.php/ rdbci/article/view/2118>. Acesso em: 31 maio 2015. 